\title{
CONTRIBUCIÓ A L'ESTUDI DEL COMERÇ AL MEDITERRANI OCCIDENTAL EN EL SEGLE XIV: \\ L'ATAC PIRÀTIC A LA COCA D'ESTEVE BORDELL
}

\author{
Josefina Mutgé I VIVES \\ Institucio Mild i Fontanals \\ (CSIC, Barcelona)
}

\section{SUMARI}

1. L'atac piràtic a Esteve Bordell: els fets.- 2. Les conscqüències i les primeres gestions. - 3. L'acord i la restitució dels danys.

Una de les causes que més varen impedir el normal desenvolupament del comerç a l'Edat Mitjana foren els freqüents atacs piratics que es produïen al mar.

En el context de la secció monogràfica del volum 24 de l'"Anuario de Estudios Medievales", dedicada precisament a l'estudi del comerç i la navegacio pel Mediterrani a l'Edat Mitjana, publiquem aquesta breu nota, en la qual donarem compte de l'atac piràtic sofert l'any 1322 pel mercader de Barcelona, Esteve Bordell. Aquesta pirateria fou una més entre les que constantment es perpetraven durant els segles que ens ocupen, però va tenir un especial ressd dins la documentació barcelonina de l'epoca'.

\footnotetext{
'La bibliografia sobre la pirateria i el corsarisme és abundant. Ja hi va prestar especial atenció el "I Congrès Intermacional de Historia Mediterránea: La Península Ibérica y el Mediterráneo centro-occidental (siglos XII-XV)", Barcelona, 1980. Altres treballs dedicats a aquest tema són, per exemple, els de C. TRASSELU, Naufragi, pirateria e doppio gioco, "Le genti del mare Mediterraneo", Nàpols, 1981, pp. 499-510; A. UNAL, Mariners, pirates i corsaris catalans a l'època medieval, Barcelona, La Magrana, 1986.; F. MARTIGNONE, Fatti di pirateria nel Mediterraneo occidentale nel secolo XV, "II Congreso Intemacional de Estudios sobre
}

"Anuario do Estudios Modiovalos", 24 (1994) 


\section{L'ATAC PIRÀTIC A ESTEVE BORDELL: ELS FETS}

L'atac piràtic a Esteve Bordell succer de la següent manera²:

El mes d'agost de l'any 1322, Esteve Bordell, mercader i ciutada de Barcelona, venia de Xipre on havia carregat una coca seva amb moltes i diverses mercaderies, el preu de les quals sobrepassava les 150.000 lliures barceloneses, i les portava amb destinació a Barcelona. El patró i els altres mercaders es varen voler desviar cap a Trapani, a l'illa de Sićlia, per tal de renovar el personal, a causa de les nombroses baixes que havien tingut per les defuncions i les malalties sofertes des que havien sortit de Xipre i també per tal de fer provisió de vitualles. Perd, quan ja es trobaven a les mars de Sićlia, davant del cap de Tre Fontane ${ }^{3}$, els va sortir del port de Trapani, on també havien renovat gents, armes i vitualles, una coca de genovesos de Savona. Al capdavant d'aquesta coca hi anaven Bernabó Cataneo "olim de la Volta" i Oberto Doria, amb molts altres genovesos gibel.lins. Atacaren la coca d'Esteve Bordell que varen matar, feriren d'altres tripulants, prengueren violentament la coca amb totes les mercaderies que portava i se la varen endur.

Aquest atac piratic fou considerat pel govern municipal de Barcelona com un greu deshonor per al rei catalano-aragonès, Jaume II, i un important perjudici economic per a la ciutat de Barcelona i per als seus habitants.

\footnotetext{
las culturas del Mediterraneo Occidental", Barcelona, 1978, pp. 297-307; M. FONTENAY-A. TENENTI, Course et piratérie méditerranéennes de la fin du Moyen Age au début du XIXe siécle, "XV Colloque Intemational d'Histoire Maritime", Paris, 1987; M. MOLAT, De la piratérie sauvage d̀ la course réglementée: XIlle-XIVe siècles, "Mélanges de l'École française de Rome. Moyen Age-Temps Modemes", 87 (1975), pp. 7-25.

${ }^{2}$ La descripció de l'atac la trobem a l'Arxiu Històric de la Ciutat de Barcelona [en endavant AHCB], Secció Consell de Cent [en endavant CC], Sèrie I: Llibre del Consell [en endavant Ll. C.], vol. 7, fols. 61 v. -62 r.

${ }^{3}$ El cap de Tre Fontane es troba a la província de Trapani, prop de la localitat de Campobello di Mazzara.
} 


\section{LES CONSEQÜĖNCIES I LES PRIMERES GESTIONS}

El govern municipal de Barcelona ja va preveure des d'un bon començament que la possible recuperació de les pèrdues produïdes per aquest atac piratic donaria lloc a moltes negociacions i produiria nombroses despeses que les persones perjudicades no podrien afrontar. Per aixd, i a fi de recaptar numerari, els consellers varen ordenar un impost a pagar sobre les mercaderies que es compraven i venien a l'engros a la ciutat, per mercaders barcelonins. Aquest impost consistia en el pagament d'una malla (mig diner) per lliura, tant el comprador com el venedor. En el cas de compravendes efectuades a mercaders estrangers, l'estranger no hauria d'abonar res, pero el ciutadà hauria de tributar un diner per lliura. Aquesta ordinació dels consellers de Barcelona fou aprovada per Jaume II el 22 de setembre de 1322. L'esmentat impost trindria vigencia fins a la Pasqua de Resurrecció de l'any $1323^{4}$.

Per altra banda, com que aquest fet es va produir dintre dels dominis del rei Frederic de Sicflia, els consellers de Barcelona no dubtaren a recórrer a ell, el 22 d'octubre de 1322, tot al.legant la concordia existent entre ambdos $\mathrm{s}^{\mathrm{s}}$. Li feien avinent que, en consideració a aquesta bona amistat, forçosament havia de desagradar-li que els genovesos o tots altres que anessin a avituallar-se a les seves terres causessin danys als súbdits del rei de la Corona d'Arago, germà seu, i als barcelonins, aixı mateix amics seus $^{6}$. Fins i tot, demanaven al rei Frederic que, en el cas que els genovesos demoressin la restitucio dels danys causats als catalans, ordenés que tots els compatriotes d'aquells que circulessin pels seus dominis fossin obligats a efectuar aquesta restitució. Els consellers de Barcelona pregaven el mo-

“Arxiu de la Corona d'Aragó, Cancelleria reial, registre 222, fol. 87 r. (1322, setembre, 29). Ed. A. de CAPMANY Y MONPALAU, Memorias históricas de la marina, comercio y artes de la antigua ciudad de Barcelona, reed. anotada a cura d'E. GIRALT Y RAVENTÓs i C. BATLLE Y GALLART (3 vols. Barcelona, Cámara Ofícial de Comencio y Navegación, 19611963), II, pp. 162-163, doc. num. 110. Citem sempre per aquesta edició.

${ }^{5} \mathrm{Hi}$ ha proves documentals de la bona amistat entre el Consell de Barcelona i el rei Frederic de Sicilia, en aquests anys. Vegeu el meu treball: El "consell" de Barcelona en la política siciliana de Jaime II, "Medioevo. Saggi e Rassegne", 20, en curs de publicació.

${ }^{6} \mathrm{AHCB}, \mathrm{CC}$, Sèrie I: Ll. C., 7, fols. 61 v. -62 r. (1322, octubre, 2): "Grave etenim et molestum debet vestra regia celsitudo gerere et habere quod per ianuenses vel alios qui exeant de locis seu terris felicis dominii regni vestri et ibidem reffrescamentum acceperint vel iuvamen, gentibus et subditis illustrissimi domini nostri regis Aragonum, karissimi fratris vestri et specialiter civibus et habitatoribus Barchinone, devotis vestris humilibus, aliquam notumenta, dampna vel iniuric infferantur". 
narca sicilià que donés resposta a aquestes peticions al ciutadà de Barcelona, Pere de Mitjavila, i al consol dels catalans a Messina, Ramon Ricard, que eren les persones que havien estat trameses a Sićlia ${ }^{7}$. Sembla que allo que els consellers demanaven a Frederic de Sićlia era la concessió del dret de marca 0 represàlia, tan emprat en aquells temps ${ }^{8}$. La mateixa data, els consellers s'adreçaven al consol de Messina i li demanaven, en nom de la ciutat, que, juntament amb el ciutadà Pere de Mitjavila, informessin bé el rei Frederic dels fets referents a l'atac a la coca d'Esteve Bordell, per tal que aquesta es pogués recuperar amb totes les mercaderies. Li deien també que Pere de Mitjavila portava una carta del rei d'Aragó i una altra de l'infant hereu Alfons, totes dues adreçades al rei de Sicflia, insistint sobre el mateix succés 9 . Un mes més tard, els consellers reiteraven al rei Frederic que, de cap manera no podia mostrar-se indiferent davant del fet que els súbdits del monarca catalano-aragonès i, sobretot, els ciutadans de Barcelona, per l'amistat que li professaven, fossin atacats per genovesos a les seves terres ${ }^{10}$.

Una mostra de l'activitat diplomàtica que va desencadenar l'acte piràtic perpetrat en la coca d'Esteve Bordell la tenim en el fet que els consellers de Barcelona no tan sols varen recórrer al rei Frederic de Sicflia, sinó que també s'adreçaren al rei de França, Carles VI el Bell, al senescal de Bellcaire (Beaucaire) i al veguer d'Aigüesmortes. El 3 de novembre de

\footnotetext{
${ }^{7}$ AHCB, CC, Sèrie I: Ll. C., 7, fols. 61 v. 62 r. (1322, octubre, 2).

${ }^{8}$ Sobre les marques en l'època que estudiem, vegeu, per exemple els treballs clàssics, però sempre útils, de: R. de MAS LATRE, Du drois de marque ou droit de représailles au Moyen Age, Paris, 1875 (Bibliothèque de l'École des Chartes, Vle série, II); J. EIGLER, Étude historique sur le droit de marque ou de représailles à Marseille aux XIIle, XIVe et XVe siecles, Marseille, 1885; A. DEL VECCHIO-E. CASANOVA, Le rappresaglie nei comuni medievali e specialmente in Firenze, Bologna, Amaldo Formi editore, 1894. Ristampa anastatica, Bologna, Zanichelli, 1974; J. MIRET I SANS, Les represalies a Catalunya durant l'Edat Mitjana. Extret de la "Revista Jurídica de Catalunya", Barcelona, 1925; R. de ALBUQUERQUE, As represálias. Estudo de História do Direito portugués (seculos XV e XVI), Lisboa, 1972, 2 vols.

'AHCB, CC, Sèrie I: L1. C., 7, fols. 62 v. -63 r. (1322, octubre, 2): "les dites letres totes presentets al dit senyor rey en Frederich e que siats curós dels affers e enformets lo senyor rey en Frederich, ab veritat, de tots los affers, en tal guisa e en tal manera que, ab la ajuda de Déu e la sua, la dita cocha se puga cobrar ab totes les mercaderies...".

${ }^{10}$ AHCB, CC, Sèrie I: Ll. C., 7, fols. 65 r. -65 v. (1322, novembre, 3): "... gentibus et subditis prefati domini regis Aragonum et precipue civibus Barchinone quos, propter nexum devocionis fidei et amoris et intime puritatis quibus vobis velut filio atque fratri domini nostri naturalis astringimur et tenemur, tamquam vestros reputare debetis, per ianuenses vel alios quoscumque egredientes de partibus sive locis felicis dominii regni vestri...dampna... aliqua inferantur".
} 
l'esmentat any de 1322, els magistrats barcelonins varen trametre Guillem Oliver i Bernat de Muntalegre, mercaders i ciutadans de Barcelona, a França, per tal de fer-hi les gestions pertinents. Aquests personatges, a més de tractar de l'atac sofert per Esteve Bordell, tenien ordres de confiscar les mercaderies d'una coca que es deia que, procedent de Romania, es dirigia al port d'Aigüesmortes ${ }^{11}$.

\section{L'ACORD I LA RESTITUCIÓ DELS DANYS}

A mitjan de l'any 1325 , continuava sense resolució l'afer de l'assalt genovès a la nau d'Esteve Bordell. Això no té res d'estrany, ja que tenim constància que fets d'aquesta mena s'arrossegaven durant molt de temps. Pero, el mes de juny de l'esmentat any de 1325, es va arribar a un acord o avinença entre el monarca catalano-aragones, la ciutat de Barcelona i els qui havien resultat perjudicats per la captura de la dita coca, de l'una banda, i els genovesos, de l'altra. Podem donar algunes notícies del procés seguit fins a arribar a aquesta avinença gràcies a les actes notarials registrades al Manual del Consell de Cent, conservat a l'Arxiu Historic de la Ciutat de Barcelona.

Cal aclarir que en l'atac a la coca d'Esteve Bordell hi participaren totes dues faccions dels genovesos, tant els gibel.lins o extrinsecs, que ocupaven Savona, com els güelfs, anomenats intrinsecs, de la ciutat de Genova. Per aixo, el primer pas d'aquest procés d'avinença fou que, al començament de l'any 1325, concretament el dia 27 de març, els consellers de Barcelona varen trametre a la ciutat de Savona, com a síndics o ambaixadors, els jurisperits Guillem Nàgera, Bernat Mascarell, Jaume de Calders i Francesc Eimeric, tots ells ciutadans de Barcelona. Per tal que aquests missatgers poguessin parlar amb coneixement de causa, els consellers de Barcelona varen demanar a la vidua de Pere de Bages, mercader i ciutada d'aquesta ciutat, que era copropietari de la nau robada, els llibres que el seu marit li havia deixat:

1. Un llibre de paper amb cobertes de pergami, de 158 folis en format major, que contenia l'estimació que els perjudicats en l'atac a la

"AHCB, CC, Sèrie I: Ll. C., 7, fol. 64 r.-v. (1322, novembre, 3). 
coca d'Esteve Bordell varen fer per ordre del rei Jaume II davant del jurisperit de Barcelona Jaume de Montjuïc.

2. Un altre llibre de paper, amb coberta de pergamí, també en format major, que contenia 30 folis amb les deposicions dels testimonis del dit atac piràtic, exposades igualment davant del jurisperit Jaume de Montjuïc. Aquest llibre portava data del 13 d'octubre de 1322.

3. Un quadern de paper de 19 fulls, en format major, on eren escrites diverses denúncies presentades a Jaume de Montjuïc per alguns dels perjudicats pels savonesos. Començava amb la següent rúbrica: "De facto depredacionis facte civibus et habitatoribus Barchinone per ianuenses de Sahona". Portava data del 3 de febrer de 1323.

D'aquests llibres, se'n féu càrrec Francesc Eimeric, el qual es va comprometre a retornar-los en tornar del viatge a Savona ${ }^{12}$.

Mentre aquests primers procuradors eren enviats a l'esmentada ciutat de la Ligúria, el 12 d'abril de 1325 , a Barcelona, es va reunir el Consell de Cent Jurats, on assistiren molts dels perjudicats per l'assalt a la coca d'Esteve Bordell. També hi fou present, en representació del rei, Pere de Bell-lloc, veguer de Barcelona i del Valles. Bell-lloc va donar plena autoritat als ciutadans de Barcelona Jaume Roure, Miquel Marquet, Guillem Nagera i Arnau Dusai, per a actuar com a procuradors per la part catalano-aragonesa i pactar amb els genovesos de Savona ${ }^{13}$. Aquesta comissió no devia obtenir cap resultat, perque, dos mesos més tard, el 18 de juny de 1325, en una altra reunió del Consell de Cent, tambe amb assistencia del veguer Pere de Bell-lloc, foren autoritzats el conseller, Jaume Roure, i els ciutadans Bernat de Marimon, Pere Rovira i Simó d'Olzet, per tal de negociar amb els nuncis de Savona, que llavors es trobaven a Barcelona, sobre la restitucio de la coca capturada ${ }^{14}$. Sembla que els genovesos de Savona s'avingueren a anar pagant determinades quantitants que s'anirien deduint de l'import total pel qual era valorada la roberia. Els nuncis catalans varen exposar aquest inici d'acord amb els de Savona a la sessió del Consell de Cent reunit el 19 de juliol de $1325^{15}$.

${ }^{12}$ AHCB, CC, Sèrie XIII: Manual del Consell de Cent [en endavant Manual], vol. 1, fols. 24 r. -25 r. (1327, manc, 27).

${ }^{13} \mathrm{AHCB}, \mathrm{CC}$, Sèrie XIII: Manual, 1, fols. 26 v. -27 v. (1325, abril, 12).

${ }^{14}$ AHCB, CC, Sèrie XIII: Manual, 1, fols. 25 r-26 r. (1325, juny, 18).

${ }^{15}$ AHCB, CC, Sèrie XIII: Manual, 1, fols. 28 r. -29 r. (1325, juliol, 19). 
Per altra banda, per aquests mateixos dies, el Comú de la ciutat de Gènova havia tramès els ambaixadors Nicola Doria i Antonio Camilla al rei Jaume II per a tractar de la repetida restitució de la coca d'Esteve Bordell i de les mercaderies que portava. En el Consell de Cent celebrat el dia 27 de juliol es varen designar, per actuar en nom del rei i de la ciutat de Barcelona els ciutadans barcelonins Bernat de Marimon i Burget de Sarrià, jurisperits, i el mercader Bernat Mascarell. Es concretava que si algun d'aquests procuradors, per qualsevol motiu, no podia actuar, podien fer-ho els altres dos ${ }^{16}$.

En aquest mateix estiu de l'any 1325, després d'efectuades les negociacions, els genovesos es comprometeren a arranjar la següent composició: pagarien 62.061 perpres d'or ${ }^{17}$ a Pera ${ }^{18}$, a la Romania (Imperi bizant I); 6.465 lliures genoveses a Savona; i 74.000 lliures barceloneses, que s'obtindrien d'una gabella que seria exigida a l'esmentada ciutat de Savona, consistent en el pagament de 4 sous per cada mina ${ }^{19}$ de sal. També abonarien 2.700 perpres d'or, en compensació de la coca i de les eixàrcies que hi havia en aquesta ${ }^{20}$. El 13 de setembre de 1325 eren atorgats plens poders a Bernat Rovira, Berenguer Dusai i Simó Dusai, mercaders i ciutadans de Barcelona, per a rebre les expressades quantitats. Havien de traslladar-se a Savona per tal d'obtenir que el Comú d'aquesta ciutat s'avingués també a l'acord de Genova, atesa la vinculació política i comercial entre ambdues

${ }^{16} \mathrm{AHCB}, \mathrm{CC}$, Sèrie XIII: Manual, 1, fols. 29 r.-30 r. (1325, juliol, 27).

${ }^{17}$ El perpre era el nom donat a la moneda bizantina d'or en el segle XIII. La paraula deriva del grec hyperpyros. Va ser moneda corrent en el territori de Gallípolis en temps de Ramon Muntaner. Fins al regnat de Joan Ducas (1222-1255) va ser d'or. Ducas l'encunya amb la meitat d'aliatge. Miquel VIII Paleỏleg (1261-1282) encara n'augmentà l'aliatge i Andrònic (1282-1328) encara més. De 24 parts només, n'hi havia 9 d'or fi (F. MATEU $Y$ LLOPIS, Glosario Hispánico de Numisinática, Barcelona, 1946, p. 159).

${ }^{18}$ Pera era un barri de la ciutat de Constantinoble. Actualment és conegut amb el nom de Beyoglu $i$ està situat a la riba nord del Com d'Or. Gènova hi tenia interessos comencials des de la segona meitat del segle XIII (T. O. DE NEGRI, Storia di Genova, Milano, 1974, pp. 376 88.

${ }^{19} \mathrm{La}$ mina era una moneda de compte a Grècia, que equivalia a 100 dracmes (F. MATEU Y LLOPIS, Glosario Hispánico de Nulnismática, p. 133).

${ }^{20}$ AHCB, CC, Sèric XIII: Manual, 1, fols. 44 r. 45 v. (1325, setembre, 13). 
ciutats $^{21}$. El 20 de setembre, abans d'emprendre el viatge, varen fer les següents puntualitzacions:

1. Els missatgers preguntaren si les 60 lliures que els havien estat assignades a cadascun, per anar a Savona, les tindrien també per anar a Constantinoble. Els respongueren que, en el cas que haguessin de traslladarse a Constantinoble, no tindrien les 60 lliures, pero el govern municipal de Barcelona es faria càrrec de les despeses que els produiria el desplaçament des de Savona a Constantinoble.

2. Els missatgers demanaren que, ja que els donaven tan poc, els subministressin almenys les vestidures. Els foren concedides 10 lliures a cadascun com a subsidi.

3. Els nuncis preguntaren si els serien restituïts els danys en el cas de ser atacats per lladres o corsaris durant el viatge. Els respongueren que serien indemnitzats en els perjudicis soferts en les seves persones, en els arnesos $i$ en els diners que havien rebut per efectuar la legació, però no en els altres béns que duguessin.

4. Els ambaixadors volien saber si a Constantinoble els serien pagades les despeses que els pogués ocasionar el fet de tenir alguna dificultat a utilitzar la moneda que portaven. Els respongueren que, si aixo els succeïa, els donarien 400 lliures.

5. Els fou concedit que, si sofrien algun accident o malaltia, no perdrien el salari.

\footnotetext{
${ }^{21}$ AHCB, CC, Sèrie XIII: Manual, 1, fols. 44 r. 45 v. (1325, setenbre, 13). Cf. també A. de CAPMANY, Meinorias, I, p. 96.

Per a comprendre la relació política i comercial entre Savona i la Corona d'Aragó, caldria conc̀ixer ben bé fins a quin punt Savona depenia de Gènova al primer quart del segle XIV. Per això, hem de remuntar-nos fins al llunyà tractat del 1202, que consistí en la submissió del Comú de Savona al Comú de Gènova, efectuada per Ugo del Carretto, podestà de Savona [Cf. P. LISCIANDRELJ], Trattati e negoziazioni politiche della Repubblica di Genova (958-1797). Regesti, "Alti della Società Ligure di Storia Patria", nuova serie I (LXXV della Raccolta) (Genova, 1960), p. 41, regesta núm. 180]; i, sobre tot, al del 1251. Segons aquest darrer tractat, els savonesos havien de ser considerats per tot arreu com a ciutadans de Gènova. Malgrat això, durant el segle XIV, el Comú de Savona maldà per desvincular-se d'aquest pacte, a fi de deslliurar-se de les càrregues fiscals que tan fortament el gravaven i que s'havien fixat en aquest mateix conveni (Vegeu G. FERRARI ALFONSO, Rapporti commerciali tra savonesi e catalani nel secolo XIV, "Atti del I Congresso Storico Liguria-Catalogna", Bordighera, 1974, pp. 243-244).

Aquesta dependència de Savona respecte de Gènova ens fa suposar que l'obligava a sotmetre's a allò que acordés aquesta darrera ciutat en l'afer que estem tractant i amb més motiu si tenim en compte que els atacants al vaixell del mercader barceloní eren genovesos gibel.lins de Savona.
} 
6. També, a petició dels missatgers, els consellers els donarien 100 sous a cadascun per a pagar un macip que els ajudés.

7. Com que els missatgers demanaren garanties de tot aixo, els consellers de Barcelona els permeteren que, de les 6.465 lliures genoveses que cobrarien a Savona, canviessin l'equivalent a 5 lliures de Barcelona $i$ les donessin a Ferrer de Fenollet o a algú altre, a fí que les hi tingués en diposit fins a la seva tornada.

8. Finalment, els consellers es varen comprometre, en nom seu i dels seus successors, a ordenar una talla entre els perjudicats per la roberia perpetrada a Esteve Bordell, per tal de pagar tot allo que aquests missatgers haguessin de bestreure del seu propi peculi, amb motiu de l'esmentada legacio, ja que ni els béns propis dels consellers ni els de la ciutat no hi eren pas obligats 22 .

Dels tres procuradors, Simo Dusai fou l'encarregat d'anar a Savona i gestionar que, efectivament, la gabella sobre la sal fos establerta i cobrarne el numerari recaptat amb aquesta imposicio. Per dur a terme aquesta gestio, Dusai havia de viure a Savona per espai d'un any. Per tot aquest any cobraria un salari de 215 lliures barceloneses de tern, que li serien pagades de la composicio que abonarien els genovesos. A manca d'aquesta, també es faria una talla entre tots els perjudicats per l'atac a la nau d'en Bordell. Si Dusai hagués de romandre a Savona més temps del previst, li fóra pagada la mateixa proporció de 215 lliures anuals, proporció que també es mantindria en el cas que amb menys temps en tingués prou. Quedava ben clar que ni els béns dels consellers ni els de la ciutat no hi eren obligats $^{23}$.

Amb motiu del viatge a Savona, els procuradors varen llogar els serveis dels traginers Bonanat Celler, Guillem Artigues, Pere Ferrer, Bernat "nunci d'en Canyet" i Bernat "nunci de Guillem Oliver". El cost total dels serveis d'aquests traginers $\mathrm{i}$ dels seus animals de carrega fou de 22 lliures, 18 sous $\mathrm{i} 1$ diner, de moneda barcelonesa de tern, en la següent proporcio: Bonanat Celler, 6 lliures, 2 sous; Guillem Artigues, 4 lliures, 8 diners; Pere Ferrer, 4 lliures, 1 sou, 8 diners; Bernat "nunci d'en Canyet", 4 lliures, 3 diners; i Bernat "nunci de Guillem Oliver", 4 lliures, 13 sous i 6 diners. Per tal de poder-los pagar immediatament, com ho exigien, els

${ }^{22}$ AHCB, CC, Sèric XIII: Manual 1, fols. 48 r. -49 r. (1325, setembre, 20).

${ }^{23}$ AHCB, CC, Sèrie XIII: Manual, 1, fols. 55 r. -56 r. (1325, setembre, 20). 
consellers de Barcelona es veieren obligats a demanar un préstec a Pere Rovira i Ferrer de Fenollet, mercaders i ciutadans de Barcelona, els quals el varen bestreure, la meitat cadascun. El 15 de novembre de 1325 , els magistrats municipals de Barcelona reconeixien a cadascun d'aquests prestadors un deute d' 11 lliures, 9 sous i 1 dbol, que s'obligaven a pagar-los dels primers diners obtinguts quan es comencés a cobrar la indemnització dels genovesos. Si aquesta indemnització no s'arribava a percebre, els consellers aplicarien una talla entre els perjudicats de l'atac piratic a Bordell ${ }^{24}$.

Des de Savona, l'11 de novembre de 1325, els tres procuradors varen escriure al govern municipal de Barcelona tot preguntant si, en el cas que s'haguessin de traslladar a terres de Romania, podrien pagar les despeses que aixo els ocasionés de la mateixa restitució pactada amb els genovesos. El Consell de Cent Jurats, reunit el dia 28 del citat mes de novembre, acorda que els procuradors poguessin fer ús dels diners que desembossarien els genovesos per a una possible anada a Romania ${ }^{25}$.

Tot aquest llarg procés de res no va servir: Savona no es volgué sotmetre a les condicions de l'avinença i Genova es nega a ratificar la composició a que s'havien compromès els seus ambaixadors Nicola Doria i Antonio Camilla. Davant d'aquesta mala voluntat per part dels genovesos, l'11 de febrer de 1326, el govern municipal de Barcelona ordenà als ambaixadors de tornar a Barcelona, però manà a Simó Dusai que, abans de sortir de Savona, protestés, mijançant un document públic, per la infracció del tractat $^{26}$.

La mateixa data, els consellers de Barcelona demanaven a Conrado Doria, almirall del rei de Sićlia, que ajudés Simó Dusai, que romania encara a Savona, a fer aquesta protesta o reclamació pública. També ho demanaven a Cristiano Spinola, un altre oficial del rei Frederic ${ }^{27}$.

${ }^{24}$ AHCB, CC, Sèrie XIII: Manual, 1, fols. 64 r. -65 v. (1325, novembre, 15).

${ }^{25}$ AHCB, CC, Série XIII: Manual, 1, fols. 66 v. -67 v. (1325, novembre, 28).

26"...pensets de protestar ab notari públich on la forma que.us trametem.. E feta la protestació, haiats la carta pública la qual ne farets fer. E, encontinent, girats lo cap e venits-vos-en" [AHCB, CC, Sèrie I: Ll. C., 9, fols. 37 v.-38 r. (1326, febrer, II). Ed. A. de CapMANY, Memorias, II, p. 178, doc. $n^{0}$ 119; cita al vol. I, p. 96].

${ }^{27} \mathrm{AHCB}, \mathrm{CC}$, Sc̀rie I, Ll. C., 9, fols. 38 r.-v. (1326, febrer, 11) : "... nobilitutem vestram affectuose prout possumus depreca!nur quatenus, ob honorem prefati domini regis Aragonum et ipsius civitatis nostronumque precaminum interventu, placeat vobis eundem Simonem in agendis per eum dirigere et iuvare, sibique assistere in premissis, consilio, auxilio et favore, sic quod, vestro mediante suffragio, idem Simon pro dicto negocio cum effectu valeat protestari et se de dictis partibus expedire libere et secure..." 
Malgrat el que havia succeït, els consellers designats per al 1327 no volgueren renunciar encara a la restitució dels danys ocasionats amb motiu de l'atac piràtic perpetrat a Esteve Bordell. Per aixd, al començament del 1327, ens consta la designació de nous procuradors per anar a Savona a cobrar les quantitats promeses pels genovesos: Simó d'Olzet i Pere Comte. Novament es va necessitar numerari per a cobrir les despeses de la legació. En aquesta ocasio foren Bernat de Marimon, Pere Rovira, Barceló Dusai, canviador, Berenguer Ros, Jaume de Gualbes, Bernat Serra, Francesc Eimeric, Ferrer de Fenollet, Pere de Bages (fill del que havia estat copropietari del vaixell assaltat, vegeu el text corresponent a la nota 12) i Bernat Mascarell, ciutadans de Barcelona. Entre tots varen fer un préstec de 100 lliures en moneda barcelonesa (10 lliures cadascun), les quals es dipositaren a la Taula de Canvi de Barceló Dusai, canviador de Barcelona. El 6 de febrer de 1327, els magistrats barcelonins es varen comprometre a retornar el préstec fet per aquestes persones amb els diners que encara tenien l'esperança de cobrar dels genovesos. A més d'aquestes 100 lliures, els consellers els en varen assignar 10 més a cadascun en compensació de les mercaderies que tenien a la coca d'en Bordell. Si els genovesos no pagaven, se n'haurien de fer càrrec els perjudicats mitjançant una talla ${ }^{28}$.

El 15 de febrer de 1327, el rei Jaume II, en nom propi i de tots els que havien rebut algun dany en la roberia perpetrada a Bordell, declarava que res més no es demanaria als genovesos per aquest assalt, sempre que ells complissin el tracte de composició a que s'havien compromès. Aixl ho expressava el sobirà a Bonifacio de Camulio, notari i síndic genovès ${ }^{29}$. Aquest personatge, al seu torn, el 17 de febrer, s'obligava a pagar 20.000 lliures genoveses a Simó d'Olzet i a Pere Comte, en el termini d'un mes $\mathbf{i}$ vuit dies a partir de la data en que es trobarien, bé a la senescalia francesa de Bellcaire o be al lloc que els harcelonins volguessin $i$ aniria a compte dels perpres $\mathrm{i}$ de les lliures en moneda de Genova que havien de liqui$\mathrm{dar}^{30}$.

${ }^{28}$ AHCB, CC, Sèric XIII: Manual, 1, fols. 98 r.-v. (1327, fehrer, 6).

${ }^{29}$ AHCB, CC, Strie XIII: Manual, 1, fols. 99 r.-101 v. (1327, febrer, 15).

${ }^{30} \mathrm{AHCB}, \mathrm{CC}$, Serie XIII: Manual, 1, fol. 102 v. -103 v. (1327, febrer, 17): "dabo et solvam vobis, dictis procuratoribus Barchinone... infra senescalliam Bellicadri aut extra ipsam senescalliam, ubicumque vos volueritis, infra unum mensem et octo dies sequentes postquam ego et vos fuerimus ibidem presentialiter constituti, viginti mille libras ianuensium". 
Consta que, el 21 de febrer de 1327, les quantitats que havien de satisfer els genovesos ja eren a Savona $i$ es trobaven en mans de compatricis seus. En aquesta mateixa data, els consellers donaren a Simó d'Olzet $i$ a Pere Comte plens poders per a exigir i rebre aquestes quantitats com també de firmar-ne les àpoques. Igualment, la ciutat de Barcelona va facultar els esmentats ambaixadors per a perdonar els qui varen assaltar la coca d'en Bordell. Pero aquesta absolució no havia de destorbar de cap manera la transaccio $6^{31}$. En aquesta mateixa data, el govern de Barcelona va assignar 200 florins d'or, del primer desembós que fessin els genovesos, al ja esmentat notari, síndic i procurador, Bonifacio de Camulio, en compensació pels treballs que va tenir per aconseguir la composició amb la república ligur ${ }^{32}$. També li assignaren 300 florins dels primers diners que obtinguessin de la gabella de la sal ${ }^{33}$.

Cal fer menció abans d'acabar que Joan de la Gautrú, mercader i ciutada de Barcelona, juntament amb els seus germans, tenien a la coca d'Esteve Bordell una quantitat de mercaderies valorada en 2.300 lliures turoneses. Aquests germans, pel seu compte, varen demanar al rei Carles IV el Bell de França que els donés llicència de marca contra els genovesos, llicència que els fou concedida el 8 de febrer de 1326, segons consta en un document expedit per la senescalia de Bellcaire ${ }^{34}$. Quan aquests germans es disposaren a executar el dret de marca, foren advertits per Jaume II, pels consellers de Barcelona i pels altres damnificats per l'atac a la coca d'Esteve Bordell que aixo podia obstaculitzar l'avinença a que s'havia arribat amb els ligurs i que seria millor per a tots que també ells s'acollissin a la composició concertada. Per aixo, el 20 de juny de 1327, Joan de la Gautrú, en nom propi i dels seus germans, renunciava a la marca que els havia estat atorgada pel monarca frances ${ }^{35}$.

\footnotetext{
${ }^{31}$ AHCB, CC, Sèrie XIII: Manual, 1, fols. 104 r-106 v. (1327, febrer, 21). Pocs dies més endavant, el 29 de febrer, el rei Jaume II va designar els mateixos procuradors elegits pels consellers de Barcelona, Simó d'Olzet i Perc Comte, també com a representants seus, per a rebre les indemnitzacions dels que atacuren el vaixcll de Bordell (AHCB, CC, Sèrie XIII: Manual, 1, fols. 101 v. -102 v.).

${ }^{32}$ AHCB, CC, Sèrie XIII: Manual 1, fols. 107 r.-v. (1327, febrer, 21).

${ }^{33}$ AHCB, CC, Sèrie XIII: Manual, 1, fols. 107 v.-108 r. (1327, febrer, 21).

${ }^{34}$ AHCB, CC, Sèrie XIII: Manual, 1, fols. 111 v.-114 v. (1327, juny, 20).

${ }^{35}$ Ibidem.
} 
No és pas segur que els genovesos arribessin a pagar la indemnització a què s'havien compromès. Sigui com vulgui, és cosa certa que atacs piràtics com el perpetrat en la coca d'Esteve Bordell varen ser la causa ocasional que desencadenà la primera guerra entre Barcelona i Genova (1330-1335). Els continuats perjudicis que rebia el comerç de Barcelona decidiren aquesta ciutat a prendre la iniciativa d'organitzar una armada i declarar la guerra pel seu compte, prescindint, fins i tot, en un principi, del sobirà catalano-aragonès, que no hi col.laborà fins que aquella ja va haverse iniciat $^{36}$.

\section{RÉSUMÉ}

L'article étudie la prise perpétrée par des pirates Génois en août 1322 du navire d'Esteve Bordell, marchand et citoyen Barcelonais, lorsqu'il retournait de Chypre, chargé de marchandises destinées a Barcelone. Dans l'article on analyse aussi la répercussion diplomatique de cet événement et les negociations ardues arrangées par les "consellers" barcelonais pour obtenir des Génois la restitution des dommages et intérêts.

\section{SUMMARY}

The article is devoted to analyse the piracy that the Genoese perpetrated in August 1322 against the ship of a merchant and citizen of Barcelona, named Esteve Bordell, when he came back from Cyprus, loaded with merchandise bound for Barcelona. The article also analyses the diplomatic repercussions of this event and the arduous negotiations undertaken by the "consellers" of Barcelona to obtain reparations from the Genoese.

\footnotetext{
${ }^{36} \mathrm{~J}$. MUTGÉ VIVFS, El "consell" de Barcelona en la guerra catalano-genovesa durante el reinado de Alfonso el Benigno, "Anuario de Estudios Medievales", 2 (1965), pp. 229-256.
} 